\title{
Manufacturing Enterprise Integration Using Simulation Software to Coordinate Budget Planning
}

\author{
E.J. Colville
}

Hon. Research Associate, School of Engineering, University of Tasmania, Australia

Email: respub@access.net.au

Keywords Budget simulation

\begin{abstract}
An examination of departmental planning and communication needs within an organisation, and in particular in manufacture, reveals the major importance of planning policy making and staff motivation. Clearly these are at the heart of business management and its infrastructure. A method of tackling these needs is presented using budget simulation. This involves preparation of budgets in a way which encourages participation in decision making and more effective implementation of the agreed budgets.
\end{abstract}

\section{BACKGROUND}

Recent research studies have defined the principal tasks undertaken by manufacturing managers, in addition to a need to understand the technology of their industry. These studies have outlined the principal needs for further knowledge by many engineers to assist them to take on the combined technology and business management responsibility our industries urgently need. From board membership through to the chief executive officer and the departmental managers of finance, production and marketing we need managers who have a technology background but also have skills additional to traditional engineering ones. [1,2]

Inquiries overseas in this year 2000 confirm a further extension of global subcontracting and international investment. They also reveal the effect that currency variations and drive for market share are having on manufacture, product design and productivity as well as weakness in the employment opportunities for traditional engineers in some age groups. 
The information technology revolution has reduced some of the routine tasks of professional groups, for example, engineers, accountants and lawyers, and this leaves room for this necessary broadening and an overlapping of professional activities [3,4,5]. Unless we as technical people now take up this opportunity to broaden our professional scope, others, who do not have the important and essential technology skills, will become the predominant management group. This will be to the detriment of our global competitiveness.

Incorporation of specific and clearly defined management and business skills for engineers in industry and in our university engineering courses is now essential for the future prospects of our engineers and manufacturing industries.

Not only is training and guidance required when a management position is achieved by engineers but more management training is needed during the earlier formative undergraduate years of the engineer. To assist both these needs, i.e., both plant management and education needs, a systems approach to management using a simulation of an organisation as a model for management action has been developed and successfully applied to manage a firm. Successful use of this process is reported for the management of small to medium size manufacturing operations and in manufacturing education $[6,7,8]$. It encourages participation by senior executives in the forward planning of a business, develops staff and stimulates implementation of budget plans.

Wider use of budget simulation to assist management and in particular to augment the business skills of technically trained people is therefore recommended.

\section{SIMULATION AND TECHNOLOGY TRAINED EXECUTIVES}

Industry now needs engineers and technology trained people who have expanded their horizons beyond the traditional professional engineering scope of the past. This is clear from personal observations in Australia and overseas, comments from industry development groups and manufacturers battling the combined effects of "level playing fields", and global competition.

Our manufacturing industries in particular need leaders on their boards and in senior management positions who thoroughly understand the technology of their industries and also can positively liaise with and direct the marketing, subcontracting, financial and political aspects of their firm. 
To achieve this we need to become more outward and widen our focus. We now need to apply our ability to calculate and understand probability to such items as finances, people development, customers and suppliers. The analysis [1] of these additional specific skills required by technology trained people to provide the balanced senior management responsibility so urgently needed in our manufacturing industries has already received comment

If we don't take up this challenge it will be to the detriment of our industries as they are forced to rely on such approaches as short term returns, dangerously high gearing, market share, supply side economics and movement of investment against the national interest. Many non-technical executives acting without the knowledge to cope with the rate of change in technology, international communications and social structure change are unable to manage efficiently.

Adding to this weakness has been the abdication of professional engineering institutions, in both Australia and U.K., of their responsibility to specifically prescribe subjects in our university engineering faculties. They need to specifically include financial management, business knowledge and people development subjects in their courses by people who have experienced this need. [9] In Australia the view appears to be "we will not prescribe, it is up to the universities to interpret what we want" but what if many faculty members have little, if any, recent experience of current manufacturing industry needs. In U.K. the view was presented that " it is up to industry and universities to jointly provide the management training required for young engineers" so that the stimulus needed at the university undergraduate stage is still only halfhearted or even negligible in some cases.

A primary purpose of this paper is to present a method using simulation of a manufacturing firm's overall activity which can be used to train both young and more mature engineers in company management and later be useful in developing their overall management skills when managing an enterprise. As emphasised by Williams and Johnson [10] in a keynote address to an international manufacturing conference in Manchester in July 2000 , there are two sides to manufacture in a global economy of innovation and regulation. One a world of mechanisms, machines, materials and facilities, the other that of overall systems, management, finances, people, customers and subcontracts. As most engineers in the first category think in terms of systems, an overall systems and simulation approach to both technology and business management will bring together the many interacting groups needing the coordination of a manager. It joins the two sides of manufacture. It promotes improvement and team activity and places the accent on implementation and results. It makes senior staff part of a 
continuous planning and budgeting process. It promotes the manager as a people developer and at the same time facilitates the transition of the traditional engineer to that of manager so that he/she can take the wider responsibility so needed in our current economy.

\section{SIMULATION AND MANUFACTURING MANAGEMENT}

Five important stages in preparing a simulation [11] are:

- Entry of data describing the forward plans of the company using a user friendly Excel spread sheet allied to a description of each group of data. Almost 100 matrices covering around 1000 numerical entries are employed to describe a small to medium size enterprise. Production, supply and marketing units of activity are translated using dollar values per unit to provide a common language throughout the simulation. However as this process is reversible as outlined in figure 1 it subsequently allows transfer of budget answers, which are in financial terms, back into production unit terms to give production planning and pricing information.

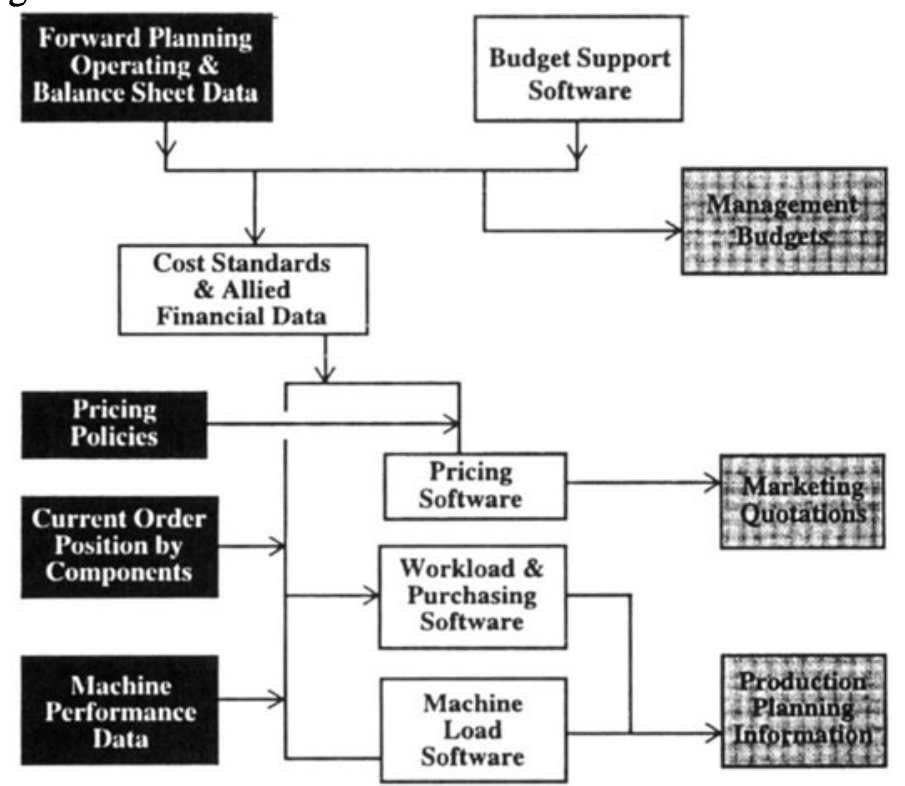

Figure 1 Coordinated Budgeting and Planning Information

- The data allows for 12 periods ahead, for example months, quarters or years. A macro operates on the above spread sheet to automatically produce a compact numerical data bank applicable to a company's total financial affairs and forward plans. 
- Software programs of two types are utilised to process the data as set out in the pull down menu of figure 2 . The first program is the basic mathematics interconnecting all the operating inputs and outputs applicable to the company and its components. Some 30 groups of equations cover balance sheet and operating criteria as well as matrices defining overhead distribution by component and department. The second program, in visual basic, presents the results in a readily accessibility compact form so that executives can bring up budgets, standard costs and financial ratios quickly, on their screens to check proposals for improvement.

- A manual describes the purpose of the program and guides users in data and budget production. Suggestions for management of the budgeting process using the programs and maintenance of the data and the budgeting process as the firm develops are provided.

- Fractional increases based on previous performance are used to align budget data predictions with executive thinking

- Ancillary programs may be prepared based on the cost standards developed by the master budget simulation program. These programs can provide a basis for pricing by the marketing department, production planning by the production planning department and purchasing implications for the finance department, all directly related to a company's overall policies.

\section{IMPLEMENTATION}

The initial task of data entry follows detailed investigation of the firm's activities. Clarification of the terms describing the firm's products, subassemblies and accounts categories is followed by meetings with the department heads and CEO to consider their needs and views to be fed into the budget. Trials follow using the simulation and meetings take place to coordinate plans and iron out anomalies and differences of opinion. A joint plan is agreed which the key executives are prepared to positively implement. At this time alignment of the company's book categories with the simulation descriptions allows later comparison between budget and actual performance as the budget unfolds.

The next phase of operation is that of managing using the budget process to guide the company's activities. Responsibility is defined as to who should call budget meetings in which progress is reported and minutes taken. The person responsible for the maintenance of the system also needs to be defined. The key to this process is that if people own the plan and believe in 
it, they are more likely to push it through despite obstacles encountered on the way.

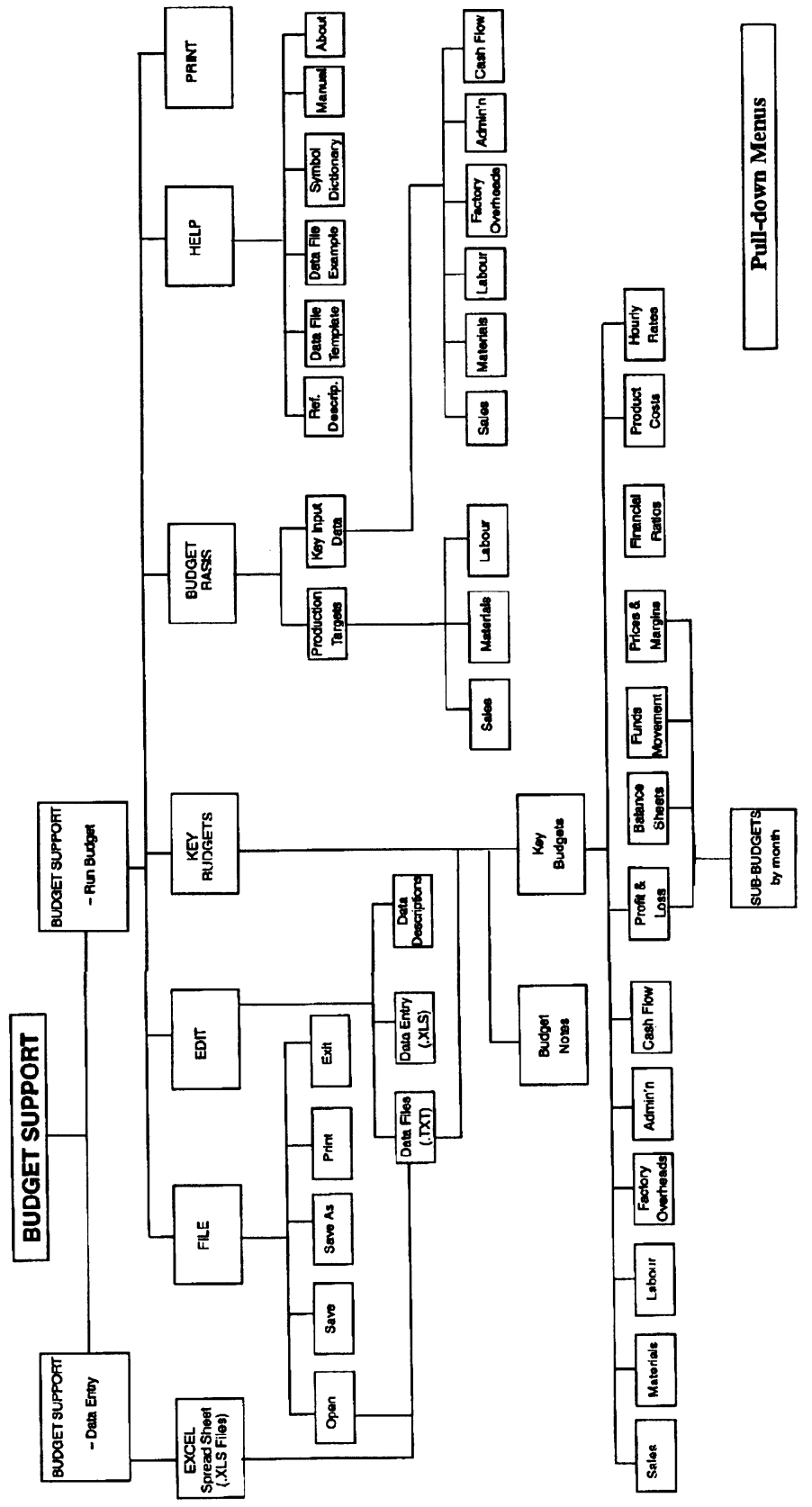

Figure 2 Pulldown menu of main Budget Support Program 
Some points to watch, applicable to most innovation, are the following:

- Patience with introduction may be needed as this process provides long term benefits and security while many managers are primarily interested in short term returns.

- Managers who operate in a hierarchical fashion can be frightened of sharing information and improving communication which is fundamental to this improvement process. They sometimes resort to the "our business is different" attitude.

- The coordinator needs to have an insight into the potential of computer programming as well as management needs.

- The production of internal budgets, involving full participation as outlined above, may be resented by those external professionals such as accountants, previously solely responsible for the budgeting process.

\section{CASE STUDIES AND RESULTS.}

This simulation developed from a need to produce budgets and test them economically and rapidly in real time. Tests in industry and in particular in printing and publishing have been carried out over some twenty years since the research was initiated.

At the same time there has been the stimulus to provide management education for mechanical and manufacturing engineers at the University of Melbourne. More recently a consolidation of industrial and educational experience applicable to practicing engineers using simulation has been undertaken with the University of Tasmania.

During this period the extraordinary development of computer software and hardware has played a significant part in advancing simulation. Results have been increased profits, better liquidity and wiser general management. This has been the result of a saving in infrastructure costs, such as accounting, estimating and liaison costs between supply production and customers, and realignment of business structure when predictions from the simulation dictate this.

The ability to meet the needs and timing of macroeconomic change and revise standards by testing the effect of radical technical, financial and process changes has been a feature of this process. An example is movement from vertical to horizontal integration as buyer- sellers relationship change. Using this process the traditional accounting and skills needed to manage people, customer relations and subcontracts in a manufacturing enterprise can be embraced by engineers. 


\section{CONCLUSION}

The budget support system described meets two important needs of current management. First the provision of economic budgets quickly as business climates change. Second it encourages a high degree of participation by senior executives and their staff. This results in efficient implementation of forward plans as a result of team work. The procedures outlined shorten the lines of communication and promote flexibility, vital to being competitive in the current global market.

As a result of an increased awareness in UK and Australia of the need for more competitive manufacturing management, current activities include promotion of this simulation approach for manufacturing industries in Australia, United Kingdom and South East Asia.

\section{REFERENCES}

[1] Colville E.J., (1999). Advancing Medium Size Manufacturing Enterprises through Management by Engineers. Doctoral Thesis, Univ. of Tas. (Inc. 73 refs. \& software).

[2] Colville E.J., (2000). General Management Opportunities for Maintenance Engineers. ICOMS 2000, $4^{\text {th }}$ International Conference of Maintenance Societies, Wollongong, N.S.W. May. Proceedings paper 076.

[3] Colville E.J., (2000). Management by Engineers. EIS 2000, $2^{\text {nd }}$ ICSC Symposium on Engineering of Intelligent Systems, Paisley, Scotland, June Proceedings p. 334

[4] Colville E.J., (2000). Strengthening Production by Extending Engineering Skills. Special ICPR 2000, International Conference on Production Research, Bangkok, Thailand Aug.

[5] Colville E.J., (2000). Engineers Managing Businesses. ICME 2000, $8^{\text {th }}$ International Conference on Manufacturing Engineering, Sydney, N.S.W., Aug paper 157.

[6] Colville E.J., (1999). Manufacturing Management Improvement through Rapid Production of Budgets. IPMM 99, $2^{\text {nd }}$ International Conference on Intelligent Processing and Manufacturing of Materials, Hawaii, USA, July Proceedings p. 649.

[7] Colville E.J., (1986). Management Information Systems for Small Manufacturers. Society of Automotive Engineers International Conference, Auckland, New Zealand. P. 156

[8] Colville E.J., (1992). Mathematical Simulation of a Manufacturing Concern. An Important Part of Engineering Management Education. ACEME, Sydney, N.S.W. April Proceedings.

[9] Personal communications, (2000), I.E.Aust , Canberra, May, and I.Mech.E. London, July.

[10] Williams D.J., and Johnson.W., (2000). Hard and Soft approaches to Manufacturing: Which is the most important? Keynote Address - MATADOR Manufacturing Conference, Manchester UK July.

[12] Colville E.J., (1997) Budget Support - A Management and Development Program. Research Publications, Vermont, Victoria. 